Cite this: Phys. Chem. Chem. Phys., 2014, 16, 4892

Received 26th October 2013 Accepted 7th January 2014

DOI: $10.1039 / c 3 c p 54531 \mathrm{~h}$

www.rsc.org/pccp

\section{The unexpected activity of Pd nanoparticles prepared using a non-ionic surfactant template}

\author{
N. A. Al Abass, G. Denuault* and D. Pletcher \\ Pd deposits on vitreous carbon substrates were prepared by electrodeposition from liquid crystal phases \\ (both micellar and hexagonal phases) consisting of self-assembled non-ionic surfactant molecules. The \\ morphology of the deposits varied significantly with the concentration of the surfactant but all are made \\ up of aggregated nanoparticles circa $9 \mathrm{~nm}$ in diameter. The deposits from the micellar phase of the \\ surfactant offer the largest electroactive area and specific activity for the hydrogen evolution, oxygen \\ evolution and reduction reactions and formic acid and ethanol oxidations. Unexpectedly the deposits \\ lead to an increase in catalytic activity far in excess of that expected from an enhancement in \\ electroactive area.
}

\section{Introduction}

Metallic nanoparticles, particularly those of noble metals, are of considerable importance for their applications in catalysis and fuel cells. Fundamentally they are interesting for their unusual physical and chemical properties due to their size and shape. ${ }^{1-3}$ Generally, they owe their large catalytic activity per gram to their high surface area to volume ratio but often nanoparticles are facetted and the large proportion of surface atoms located on edges and corners further enhances their reactivity. ${ }^{4}$

Here we report the electrochemical activity of surfaces with controlled size and dispersion of Pd nanoparticles obtained by electrodeposition from a palladium salt in the presence of a molecular template consisting of self-assembled surfactant molecules. The nanoparticles were grown under potentiostatic conditions on glassy carbon (GC) substrates in different aqueous mixtures of octaethyleneglycol mono-hexadecyl ether $\left(\mathrm{C}_{16} \mathrm{EO}_{8}\right)$, a non-ionic surfactant known to behave as a lyotropic liquid crystal and to form well characterised phases defined by the temperature and surfactant to water mass ratio. ${ }^{5-7}$ The plating mixtures were chosen to investigate the influence of the micellar and hexagonal phases of the surfactant on the deposits. We used high overpotentials to operate under mass transfer control so as to produce particles. This approach differs from previous studies of Pd electrodeposition using a $\mathrm{C}_{16} \mathrm{EO}_{8}$ template which was conducted on metal substrates at low overpotentials so as to operate under kinetic control and grow uniform films, and specifically with the hexagonal phase to produce nanostructured films with well-defined tubular pores. ${ }^{8-12}$ We controlled the

Chemistry, University of Southampton, Southampton, SO17 1BJ, UK.

E-mail: gd@soton.ac.uk nucleation and growth of the nanoparticles with the deposition potential and the amount of Pd formed with the charge passed during the deposition. A separate study was carried out to investigate the effect of the surfactant on the nucleation and growth of the Pd nanoparticles. ${ }^{13}$

In the next sections we report the preparation and characterisation of the modified GC electrodes. Scanning electron microscopy, voltammetry and chronoamperometry were used to investigate the palladium centres. The particle size, electroactive area and roughness factor were estimated. The electrocatalytic activity of the particles was assessed by voltammetry using the oxidation of ethanol and formic acid, the evolution of hydrogen and oxygen and the reduction of oxygen as test reactions. Overall we find that the electrochemical activity of the nanoparticles depends on the presence of the surfactant template during preparation of the deposits and on the amount of surfactant used. We also show that deposits prepared using the surfactant template are significantly more active than expected from their electroactive area.

\section{Experimental}

Ammonium tetrachloropalladate(II) (97\%, Aldrich), octaethylene glycol monohexadecyl ether (98\% Aldrich), sulphuric acid (95\% BDH), potassium chloride ( $99.8 \%$ Fisher), potassium hydroxide ( $85 \% \mathrm{BDH})$, ethanol (99.9\% Fisher), formic acid (98\% BHD), perchloric acid $(60 \% \mathrm{BDH})$, argon $(99.9 \% \mathrm{BOC})$ and oxygen $(99.9 \%$ BOC) were all used as received. All solutions were prepared using deionised water obtained from a Whatman RO50 system combined with a Whatman STILLplus carbon filter.

The Pd plating solutions were made with varying surfactant weight ratios purposely selected to be well within the 
Table 1 Composition of the plating mixtures used to prepare the Pd deposits, the corresponding liquid crystal phase ( $\mathrm{m}$ - micellar, $\mathrm{h}$-hexagonal), consistency and $\mathrm{pH}$. In all cases the concentrations of a Pd salt and $\mathrm{KCl}$ were, respectively, 0.01 and $0.5 \mathrm{M}$

\begin{tabular}{lllll}
\hline & \multicolumn{4}{l}{ Name of mixture } \\
\cline { 2 - 5 } & $0 \%$ & $2 \%$ & $10 \%$ & $48 \%$ \\
\hline$\left(\mathrm{NH}_{4}\right)_{2} \mathrm{PdCl}_{4}(\mathrm{mg})$ & 2.8 & 2.7 & 2.4 & 1.4 \\
$\mathrm{KCl}(\mathrm{mg})$ & 35.5 & 35.1 & 32.4 & 18.6 \\
$\mathrm{H}_{2} \mathrm{O}(\mathrm{mg})$ & 961.7 & 942.2 & 865.2 & 500.0 \\
$\mathrm{C}_{16} \mathrm{EO}_{8}(\mathrm{mg})$ & 0 & 20 & 100 & 480 \\
$\mathrm{Phase}$ & - & $m$ & $m$ & h \\
Consistency & liq. & liq. & liq. & paste \\
pH & 3.27 & 3.23 & 2.95 & 2.17 \\
\hline
\end{tabular}

composition ranges known to form at room temperature the micellar (2 and 10\%) and hexagonal (48\%) liquid crystal phases in the presence of a palladium salt. ${ }^{9}$ Each mixture was prepared with a set percentage weight of $\left(\mathrm{NH}_{4}\right)_{2} \mathrm{PdCl}_{4}, \mathrm{C}_{16} \mathrm{EO}_{8}, \mathrm{KCl}$ and water such that the Pd salt concentration in the aqueous phase remained constant throughout, Table 1.

From now on all mixtures are referred to their surfactant percentage weight. The constituents were separately weighed, mixed in a glass vial and stirred using a plastic rod until the mixture appeared homogeneous. The viscosity of the mixture varies widely, typically from liquid to paste depending on the amount of surfactant. To ensure that the correct liquid crystal phase was obtained, the mixtures were then annealed at $40{ }^{\circ} \mathrm{C}$ for $30 \mathrm{~min}$, manually stirred for $2 \mathrm{~min}$ and finally placed in an ice bath for $30 \mathrm{~min}$. This process was repeated three times before allowing the mixture to cool down to room temperature. No attempt was made to remove oxygen from the mixtures. Depositions were performed at room temperature with a small volume from the stock mixtures. The latter were used for circa three weeks then discarded, but each time the annealingcooling process was carried out before use. Where required the phase was confirmed by polarisation microscopy as reported previously. ${ }^{9}$ Typically the plating mixture was observed using a polarising optical microscope (Olympus BH2) equipped with a heating/cooling stage (Linkam TMS 90). A small amount of the mixture was sandwiched between a glass slide and a cover slip and placed in the microscope between two polarisers with their axes rotated at $90^{\circ}$. The hexagonal phase is anisotropic and changes the polarisation of the light thereby producing a characteristic black and white 'fan' like optical texture with non-spherical air bubbles. In contrast the isotropic cubic and micellar phases do not alter the polarisation of the light and cannot be viewed through the crossed polarisers. Phase transitions were noted by observing changes in optical texture while slowly heating/cooling the mixture.

Chronoamperometry, cyclic and linear sweep voltammetry were carried out on a Micro Autolab type III (Ecochemie) controlled using the GPES v.4.9 software (Ecochemie). All experiments were performed in a Faraday cage with a three electrode configuration. The reference electrodes were homemade saturated calomel electrode (SCE), saturated mercury sulphate electrode (SMSE) and mercury mercurous oxide (MMO). The counter electrode was a large area platinum mesh electrode. The working electrodes were homemade from $3 \mathrm{~mm} \varnothing$ glassy carbon rods (Tokai Carbon Co. Ltd.) sealed in glass. The glassy carbon electrode was polished on silicon carbide (1200 grit) for $1 \mathrm{~min}$, then on polishing cloth (Buehler) with alumina powder (successively 5,1 , 0.3 and $0.05 \mu \mathrm{m} \varnothing$ ) for 2, 4, 8 and 16 min respectively. After each polishing step the electrode was rinsed with deionised water and cleaned in an ultrasonic bath of acetone for $15 \mathrm{~min}$ then in an ultrasonic bath of water for further $30 \mathrm{~min}$. This procedure was chosen to ensure that the electrode surface was free from old Pd particles and that its surface roughness remained constant. Unless otherwise stated all voltammograms were recorded on the first cycle.

To electrodeposit the particles all the electrodes were immersed in the plating mixtures except for the hexagonal phase which, due to its paste-like consistency, was placed onto a platinum mesh that acted as the counter electrode while the working and reference electrodes were pushed closely together into the paste. Scanning electron microscopy (SEM) images were taken using a JEOL JSM-6500F Field Emission Gun Scanning Electron Microscope (FEG-SEM).

\section{Results}

\section{Pd electrodeposition from lyotropic liquid crystal mixtures}

The electrodeposition of Pd is systematically affected by the amount of surfactant present in the plating mixture as shown in the cyclic voltammograms recorded at GC electrodes in each of the plating mixtures, Fig. 1.

These voltammograms were recorded not to produce deposits but solely for diagnostic purposes. For each mixture they have the characteristic features for the plating of a metal on a foreign substrate namely a deposition wave showing a clear nucleation loop and a stripping peak for the removal of the metal from the surface. Increasing surfactant concentrations require a greater overpotential to deposit the Pd as illustrated by the pronounced

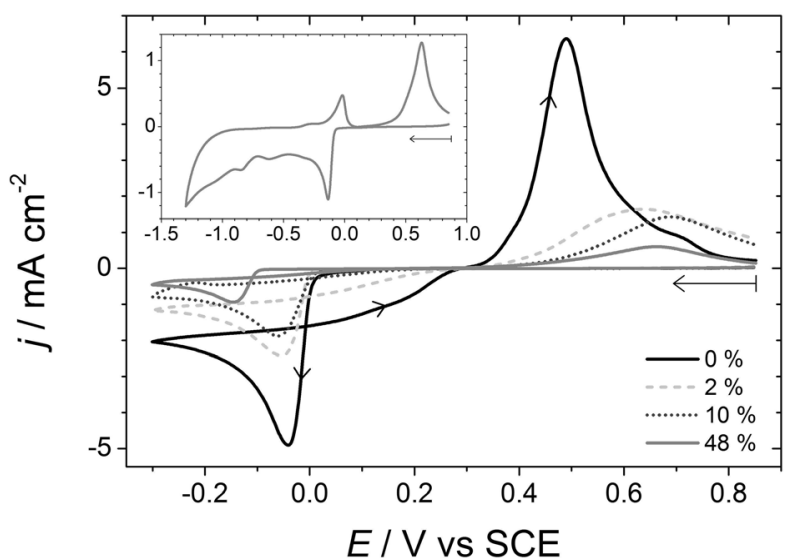

Fig. 1 Cyclic voltammograms recorded at $10 \mathrm{mV} \mathrm{s}^{-1}$ on $3 \mathrm{~mm} \varnothing$ glassy carbon discs in aerated $10 \mathrm{mM}\left(\mathrm{NH}_{4}\right)_{2} \mathrm{PdCl}_{4}+0.5 \mathrm{M} \mathrm{KCl}$ with $0,2,10$ and $48 \mathrm{wt} \%$ of $\mathrm{C}_{16} \mathrm{EO}_{8}$ as indicated by the legend. The inset shows the voltammogram recorded in the $48 \%$ mixture when reversing the sweep at $-1.3 \mathrm{~V}$ 
shift of the deposition wave towards negative potentials for the $48 \%$ mixture. This is thought to reflect the adsorption of the surfactant on the substrate. The peak current for the deposition decreases when going from no surfactant to the micellar phase then to the hexagonal phase and this reflects the lower rate of mass transport arising from the increasing viscosity of the mixture. As shown in the inset of Fig. 1 the characteristic voltammetric features of Pd, peaks for hydrogen adsorption, absorption and extraction (small stripping peak at circa $-0.1 \mathrm{~V}$ ), are observed when taking the lower reversal potentials to $-1.3 \mathrm{~V}$ but are suppressed with increasing surfactant content. Similarly the stripping peak is much smaller in the presence of the surfactant thereby indicating that a smaller amount of Pd is deposited during the potential scan.

To assess the electrochemical activity of the modified electrodes Pd was electrodeposited by stepping from +0.7 V vs. SCE, a potential sufficiently positive to ensure no Pd would remain on the surface, to $-0.3 \mathrm{~V} v s$. SCE, a potential sufficiently negative that plating would occur even with the most concentrated surfactant mixture and also sufficiently negative to ensure that growth would be mass transport controlled. For all mixtures the deposition was stopped when the charge reached $63.7 \mathrm{mC} \mathrm{cm}^{-2}$, a value such that the largest deposits found on the edges of the electrodes were never bigger than a few micrometres (edge effects at the GC-glass boundary lead to higher current densities and produce larger particles than in the centre of the electrode). The resulting chronoamperograms have the characteristic shape for an electrochemically driven, diffusion controlled (the current is proportional to $t^{-1 / 2}$ at long times), nucleation and growth process as illustrated in Fig. 2 for the $0 \%$ mixture. The current transients were systematically analysed to assess the influence of the surfactant template on the nucleation and growth parameters. ${ }^{13}$

After the potential steps the deposits formed were easily seen by eye as a dull grey coating. The deposits prepared using the surfactant template were found to be mechanically stable as they remained on the GC after rubbing against a clean polishing cloth; the $48 \%$ deposit was unaffected by rubbing while the

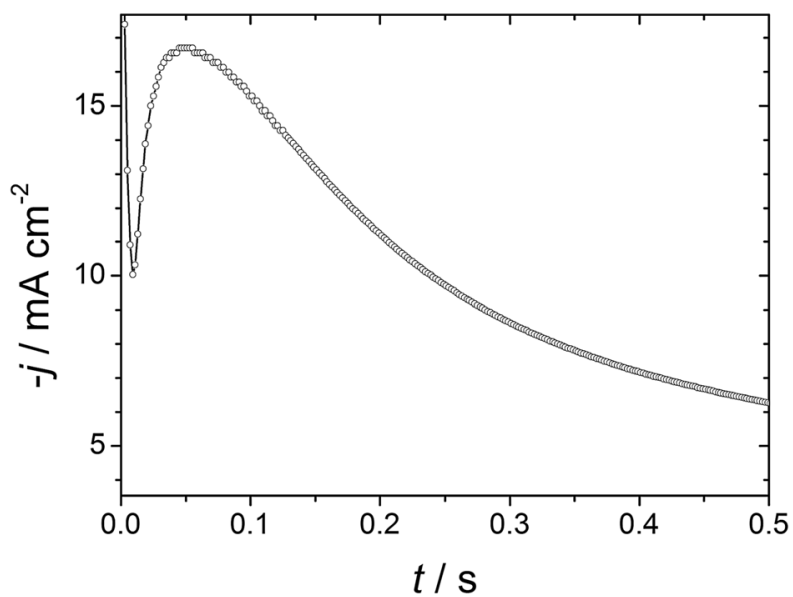

Fig. 2 Current transient recorded at $-0.3 \mathrm{~V}$ vs. SCE with a $3 \mathrm{~mm} \varnothing$ glassy carbon disc in aerated $10 \mathrm{mM}\left(\mathrm{NH}_{4}\right)_{2} \mathrm{PdCl}_{4}+0.5 \mathrm{M} \mathrm{KCl}$ without a surfactant.
2 and $10 \%$ deposits lost circa a quarter of their activity. In contrast the deposit formed without the surfactant was removed by rubbing. All deposits retained their electrochemical activity over several weeks. Fig. 3 shows typical SEM images of the Pd deposits observed in regions unaffected by edge effects and free from obvious defects (visible defects in the GC generally produced micrometre size deposits) for each of the plating solutions considered. In the absence of a surfactant, Fig. 3a, Pd is deposited as a very dense monolayer of agglomerates with a size averaging circa $100 \mathrm{~nm}$. These appear to be formed of smaller clusters, typically $25 \mathrm{~nm}$ and below, some of which are found on the GC electrode in between the agglomerates. However, as shown in the inset zooming on the deposits reveals that they consist of particles circa $11 \pm 3 \mathrm{~nm}$ in diameter. With 2 wt\% of surfactant, Fig. 3b, a very dense monolayer of smaller Pd aggregates, with sizes ranging from sub-25 nm clusters to $100 \mathrm{~nm}$ aggregates, is found. Gaps between agglomerates are smaller than those in the absence of a surfactant and it is difficult to observe the surface of the GC substrate. While this low concentration of the surfactant retains the granular texture of the deposit it clearly improves the Pd coverage. Zooming on the figure (inset) reveals that the aggregates consist of particles circa $6 \pm 3 \mathrm{~nm}$ in diameter. The $10 \%$ mixture produces deposits with a very different, almost scaly, texture, Fig. 3c. Pd is deposited as one or two layers of large flakes, several hundred $\mathrm{nm}$ across, randomly distributed over smaller aggregates. Voids reaching $100 \mathrm{~nm}$ in size can be seen between the deposits. The flakes and aggregates beneath consist of particles circa $7 \pm 3 \mathrm{~nm}$ in diameter (inset). In contrast the $48 \%$ mixture produces a monolayer of circa $100 \mathrm{~nm}$ diameter joined up granular aggregates which appear to align along parallel rows, Fig. 3d. $100 \mathrm{~nm}$ wide voids can be seen in several places indicating a lower coverage of the GC substrate compared to the previous mixtures. Zooming (inset) also reveals that the aggregates consist of particles circa $9 \pm$ $3 \mathrm{~nm}$ in diameter. All mixtures therefore produce porous deposits with aggregated particles averaging $9 \mathrm{~nm}$ in diameter but these particles appear to be more distinct with the $10 \%$ mixture. In addition, it is unlikely that the $9 \mathrm{~nm}$ centres produced from the hexagonal phase can have a nanotubular structure with a repeat of circa $6 \mathrm{~nm}$ as identified with continuous layers. ${ }^{9}$

\section{Characterization by voltammetry in acid}

The palladium deposits were characterised by voltammetry in $1 \mathrm{M}$ sulphuric acid, Fig. 4.

Irrespective of the plating mixture used the GC electrodes produce voltammograms consistent with polycrystalline Pd electrodes in acids. ${ }^{14}$ The following characteristic voltammetric signatures are observed: (a) the double layer region, (b) waves for the formation of Pd oxides, (c) a peak for the stripping of Pd oxides, (d) a peak for the adsorption of $\mathrm{H}$ on $\mathrm{Pd}$, (e) a shoulder for the absorption of $\mathrm{H}$ to form the $\alpha$-Pd hydride phase, (f) a peak for the absorption of $\mathrm{H}$ to form the $\beta$-Pd hydride phase, $(\mathrm{g})$ a peak for the extraction of $\mathrm{H}$ from the $\beta$-Pd hydride, (h) a shoulder for the extraction of $\mathrm{H}$ from the $\alpha$-Pd hydride and 

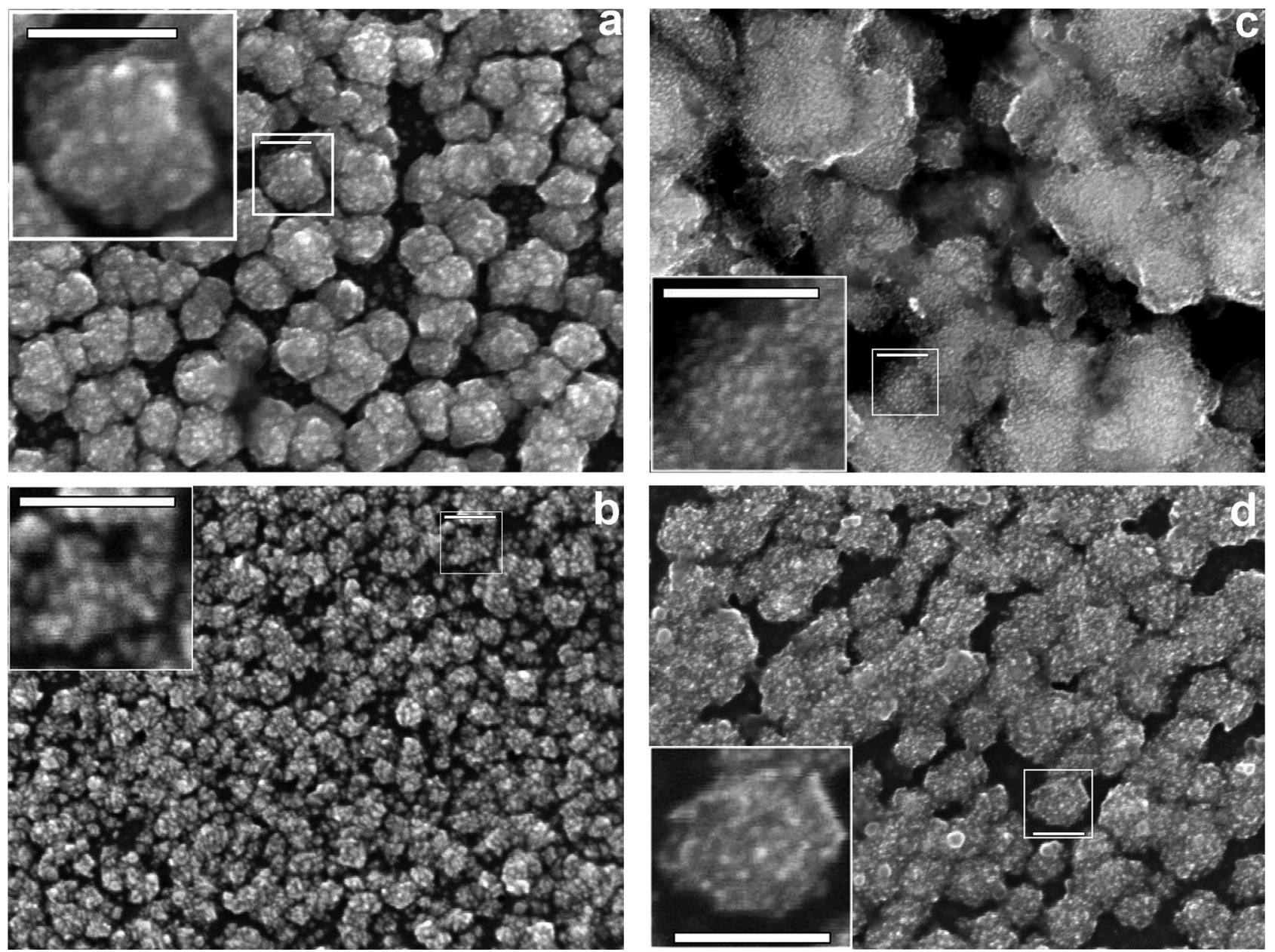

Fig. 3 FEG-SEM images of Pd structures electrodeposited on GC after stepping from $+0.7 \mathrm{~V}$ to $-0.3 \mathrm{~V}$ vs. SCE for a $63.7 \mathrm{mC} \mathrm{cm}^{-2}$ deposition charge. (a) 0 , (b) 2, (c) 10, and (d) 48 wt \% surfactant. In all cases the scale bar is $100 \mathrm{~nm}$ long.

(i) a peak for the desorption of $\mathrm{H}$ from the Pd surface. These features are significantly influenced by the amount of surfactant present in the plating mixture. The 0 and $48 \%$ mixtures present similar voltammetric features with broadly identical peak positions, shapes and magnitudes. In contrast the 2 and $10 \%$ mixtures present more resolved peaks in the hydrogen region and significantly more current in the oxide region. The oxide stripping peak current increases systematically from 0 to 2 to $10 \mathrm{wt} \%$ surfactant but decreases significantly for $48 \mathrm{wt} \%$ to a level comparable to the $0 \mathrm{wt} \%$ mixture. The trend is consistent with the morphology of the deposits observed by SEM, Fig. 3, with the deposits becoming more divided when going from the $0 \%$ to 2 and $10 \%$ mixtures but recovering a granular texture similar to the $0 \%$ mixture when prepared with $48 \mathrm{wt} \%$ surfactant.

The area under each voltammetric peak represents the charge involved in the corresponding redox process and can be used to determine the electroactive area. The latter was calculated from the oxide stripping peak after subtraction of the charge for the rearrangement of the double layer and using a conversion factor of $424 \mu \mathrm{C} \mathrm{cm}^{-2}$, the charge corresponding to the adsorption of a monolayer of Pd oxide. ${ }^{15,16}$ These data are summarised in Table 2 for the four plating mixtures.
The specific area was calculated from the mass of $\mathrm{Pd}$ deposited assuming 100\% Faradaic efficiency. Although oxygen reduction occurs during plating the concentration of oxygen, typically $230 \mu \mathrm{M}$ for a $0.5 \mathrm{M} \mathrm{KCl}$ solution at room temperature, is sufficiently small compared to that of the Pd salt to neglect its influence on the plating efficiency. Even in the very viscous hexagonal phase the plating efficiency of Pd was reported to be between 95 and $98 \%$ from electrochemical quartz microbalance experiments. $^{9}$

Even the deposit from $0 \%$ surfactant is rough and the presence of the surfactant increases the roughness further. Overall the micellar phase yields electroactive areas slightly larger than the hexagonal phase $(48 \%)$ or the plating solution without the surfactant $(0 \%)$. The $10 \%$ mixture offers the largest electroactive area with a corresponding specific area reaching circa $34 \mathrm{~m}^{2} \mathrm{~g}^{-1}$.

In the following sections we examine the electrocatalytic activity of the Pd deposits using the oxidation of formic acid and ethanol, the evolution of hydrogen and oxygen and the reduction of oxygen as test reactions. These processes are central to the development of fuel cells and electrolyzers and their kinetics is known to be very sensitive to the availability and reactivity of the electrocatalysts. 


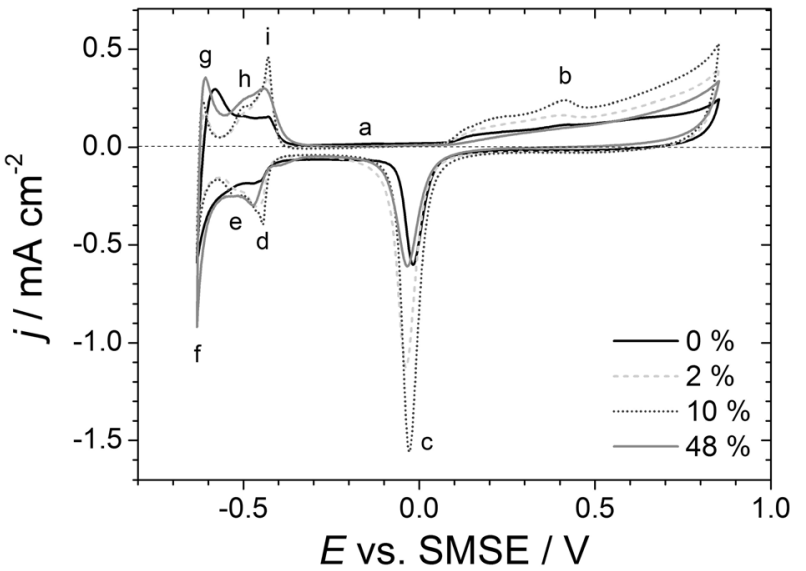

Fig. 4 Voltammograms (5th cycle) recorded in $1 \mathrm{M} \mathrm{H}_{2} \mathrm{SO}_{4}$ at $20 \mathrm{mV} \mathrm{s}^{-1}$ with $3 \mathrm{~mm} \varnothing$ glassy carbon discs decorated with Pd structures electrodeposited by stepping the potential from $+0.7 \mathrm{~V}$ to $-0.3 \mathrm{~V}$ vs. SCE up to a $63.7 \mathrm{mC} \mathrm{cm} \mathrm{cm}^{-2}$ deposition charge. The legend indicates the corresponding plating mixtures. (a) Double layer region, (b) oxide formation, (c) oxide stripping, (d) $\mathrm{H}$ adsorption, (e) $\mathrm{H}$ absorption to form $\alpha-\mathrm{PdH}$, (f) $\mathrm{H}$ absorption to form $\beta-\mathrm{PdH}$, (g) $\mathrm{H}$ extraction from $\beta-\mathrm{PdH}$, (h) $\mathrm{H}$ extraction from $\alpha-\mathrm{PdH}$, and (i) $\mathrm{H}$ desorption.

Table 2 Dependence of the Pd oxide stripping charge, $Q_{P d}$, roughness factor, $R_{\mathrm{f}}$ and specific area, $S$ on the amount of surfactant present in the plating template

\begin{tabular}{llrl}
\hline $\mathrm{C}_{16} \mathrm{EO}_{8} \mathrm{wt} \%$ & $Q_{\mathrm{Pd}}{ }^{a}\left(\mathrm{mC} \mathrm{cm}^{-2}\right)$ & $R_{\mathrm{f}}$ & $S\left(\mathrm{~m}^{2} \mathrm{~g}^{-1}\right)$ \\
\hline 0 & 1.87 & 4 & 12.7 \\
2 & 4.13 & 10 & 28.0 \\
10 & 4.98 & 12 & 33.8 \\
48 & 2.57 & 6 & 17.5
\end{tabular}

${ }^{a}$ Evaluated from the voltammograms in Fig. 4.

\section{Electrocatalytic activity: oxidation of formic acid and ethanol}

Voltammograms for the oxidation of formic acid recorded with the Pd modified GC electrodes are shown in Fig. 5. GC itself shows no activity in sulphuric acid. Interestingly the Pd deposit prepared without the surfactant only shows a small peak at around $+0.05 \mathrm{~V}$ on the forward scan. In contrast deposits prepared with the surfactant present the small peak at circa $+0.05 \mathrm{~V}$ followed by a much larger peak between +0.2 and $+0.3 \mathrm{~V}$ and a shoulder at around $+0.6 \mathrm{~V}$. For these deposits, the small peak was found to disappear on subsequent cycles (not shown). On the reverse scan the activity lost at high potentials during the formation of Pd oxide is mostly recovered when the reduction of the Pd oxide regenerates a fresh Pd surface. Overall the voltammetric features are consistent with the voltammetry for formic acid oxidation observed with different Pd electrocatalysts. ${ }^{17,18}$ While the potential of the main oxidation peak does not vary much between the electrodes for the 2, 10 and 48 wt $\%$ mixtures, the corresponding peak current density, respectively, 13, 33 and $21 \mathrm{~mA} \mathrm{~cm}{ }^{-2}$ (all taken on the forward peak), varies significantly and clearly demonstrates important differences in electrocatalytic activity. The largest oxidation current density observed ( $10 \%$ mixture) corresponds to a specific activity of $13.3 \mathrm{~A} \mathrm{~cm}^{-2} \mathrm{mg}^{-1}$.

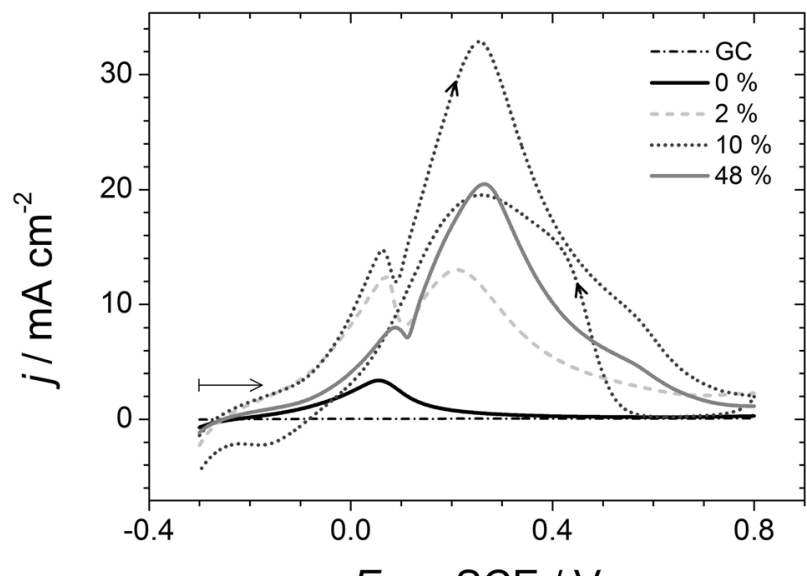

E vs. SCE / V

Fig. 5 Voltammograms for the oxidation of formic acid recorded in $\mathrm{Ar}$ purged $0.5 \mathrm{M} \mathrm{HCOOH}+0.5 \mathrm{M} \mathrm{H}_{2} \mathrm{SO}_{4}$ at $100 \mathrm{mV} \mathrm{s}^{-1}$ with $\mathrm{GC}$ electrodes decorated with the $\mathrm{Pd}$ deposits. The legend indicates the corresponding plating mixtures. For clarity the reverse sweep is only shown for the $10 \%$ mixture.

Fig. 6 presents the voltammograms recorded for the oxidation of ethanol in $0.1 \mathrm{M} \mathrm{KOH}$.

While peak positions are similar for all electrodes, the oxidation peak currents present large variations depending on the amount of surfactant used to prepare the plating template. For the 0,2,10 and $48 \mathrm{wt} \%$ mixtures the peak current densities measured on the forward scan are, respectively, 6, 16, 58 and $19 \mathrm{~mA} \mathrm{~cm}^{-2}$. The bare GC electrode is not active but all the Pd modified electrodes show good activity in the $\mathrm{KOH}$ solution, in agreement with previous reports. ${ }^{19}$ Once again the electrode electroplated with $10 \mathrm{wt} \%$ surfactant stands out to be the most active (nine times more than the electrode prepared without the surfactant and three times more than that prepared with the hexagonal phase) and reaches a specific

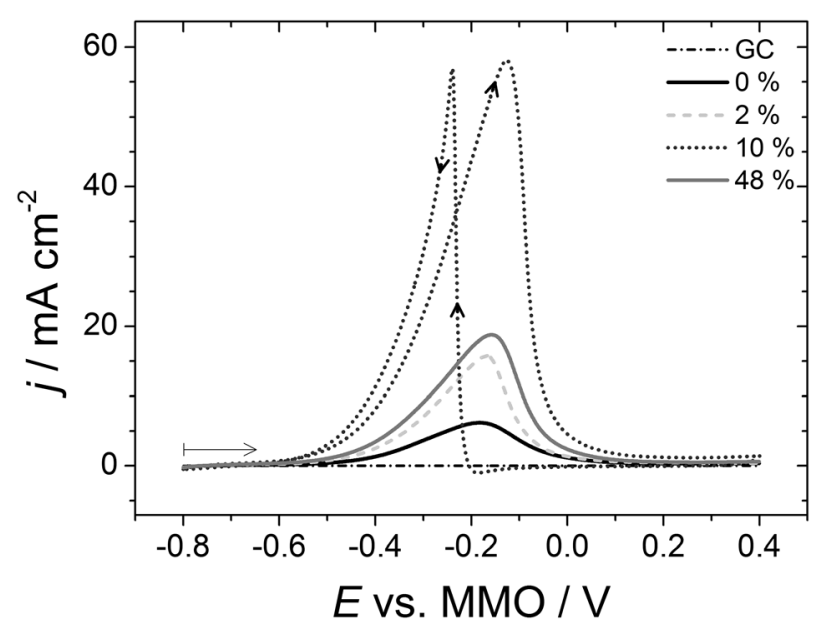

Fig. 6 Voltammograms for the oxidation of ethanol recorded in $\mathrm{Ar}$ purged $0.5 \mathrm{M}$ ethanol $+0.1 \mathrm{M} \mathrm{KOH}$ at $100 \mathrm{mV} \mathrm{s}^{-1}$ with $\mathrm{GC}$ electrodes decorated with the $\mathrm{Pd}$ deposits. The legend indicates the corresponding plating mixtures. For clarity the reverse sweep is only shown for the $10 \%$ mixture. 
activity over $23.4 \mathrm{~A} \mathrm{~cm}^{-2} \mathrm{mg}^{-1}$. The sharp drop in current after the forward oxidation peak is consistent with the loss of activity due to the formation of $\mathrm{Pd}$ oxide $^{20}$ and the recovery of the activity observed on the reverse scan is consistent with a fresh electrode surface resulting from the removal of the Pd oxide.

\section{Electrocatalytic activity: oxygen and hydrogen evolution}

Fig. 7 presents voltammograms for the hydrogen evolution reaction recorded with the $\mathrm{Pd}$ modified GC electrodes. The bare glassy carbon electrode shows no activity for hydrogen evolution while the Pd deposits prepared without the surfactant show modest activity. Those prepared with the 2 and $48 \%$ mixtures are much more active but their activity is dwarfed by that of the deposits prepared with the $10 \%$ mixture. At $-0.1 \mathrm{~V}$ the latter amounts to a specific activity circa $1.0 \mathrm{~A} \mathrm{~cm}^{-2} \mathrm{mg}^{-1}$ and the current densities scaled as follows with respect to the 10\% solution: $j_{10 \%}=4 \times j_{2 \%}=4 \times j_{48 \%}=26 \times j_{0 \%}$.

The voltammetry for the oxygen evolution reaction presents a similar pattern, Fig. 8. The bare GC electrode and Pd deposits prepared without the surfactant have poor activity, the $2 \%$ and $48 \%$ mixtures have roughly similar performance with much larger current densities and the $10 \%$ mixture produces even larger current densities amounting to a specific activity around $52.4 \mathrm{~A} \mathrm{~cm}^{-2} \mathrm{mg}^{-1}$ at $+1.2 \mathrm{~V}$. At this potential the current densities scale as follows with respect to the $10 \%$ solution: $j_{10 \%}=2 \times j_{2 \%}=3 \times j_{48 \%}=25 \times j_{0 \%}$.

\section{Electrocatalytic activity: oxygen reduction}

Fig. 9 shows the voltammograms recorded for the reduction of dissolved oxygen under alkaline conditions. In the presence of Pd the voltammograms have two reduction waves typical of the reduction of oxygen via the peroxide route but the first reduction peak is much more pronounced when the Pd deposit is prepared using the surfactant template. The electrodes perform in a similar way as for the oxygen and hydrogen evolution reactions with bare GC and the $0 \%$ mixture yielding very low activity, the 2 and $48 \%$ mixtures yielding similar activity and the $10 \%$ mixture

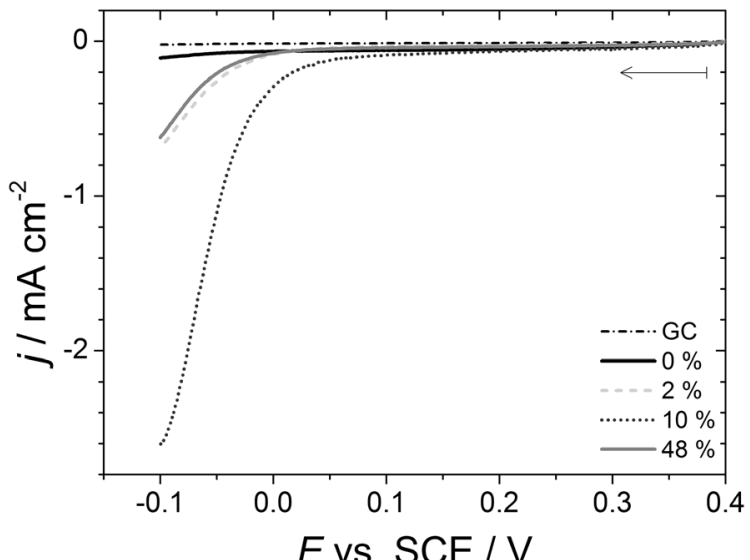

Fig. 7 Linear sweep voltammograms for the evolution of $\mathrm{H}$ recorded in $\mathrm{Ar}$ purged $0.5 \mathrm{M} \mathrm{HClO}_{4}$ at $100 \mathrm{mV} \mathrm{s}^{-1}$ with GC electrodes decorated with the $\mathrm{Pd}$ deposits. The legend indicates the corresponding plating mixtures.

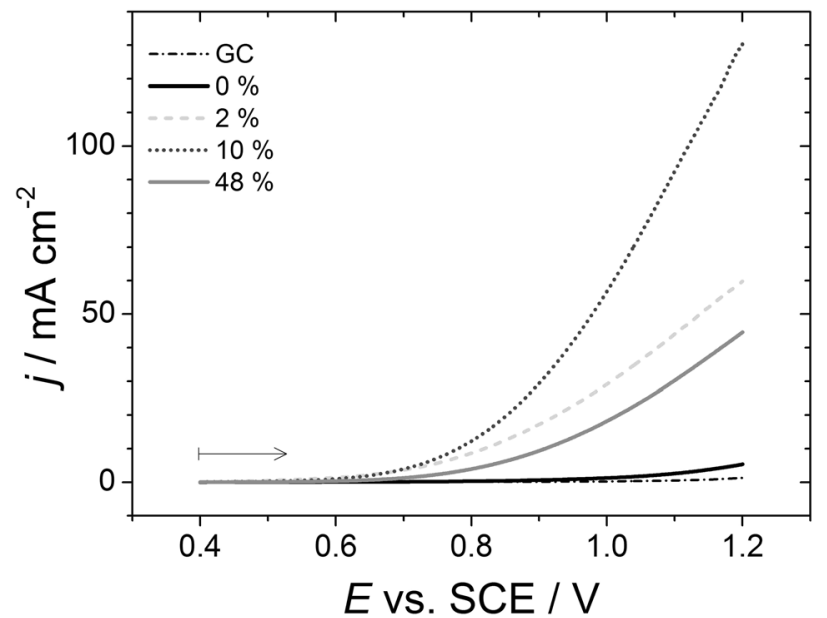

Fig. 8 Linear sweep voltammograms for the evolution of $\mathrm{O}_{2}$ recorded in Ar purged $0.5 \mathrm{M}$ ethanol $+0.5 \mathrm{M} \mathrm{KOH}$ at $100 \mathrm{mV} \mathrm{s}^{-1}$ with $\mathrm{GC}$ electrodes decorated with the Pd deposits. The legend indicates the corresponding plating mixtures.

providing the best performance. At circa $-0.11 \mathrm{~V}$ the specific activity of the deposits prepared with the $10 \%$ mixture amounts to $0.7 \mathrm{~A} \mathrm{~cm}^{-2} \mathrm{mg}^{-1}$ and the current densities scale as follows with respect to this mixture: $j_{10 \%}=2 \times j_{2 \%}=3 \times j_{48 \%}=39 \times j_{0 \%}$.

Similar voltammograms were recorded in oxygen saturated $0.5 \mathrm{M} \mathrm{HClO}_{4}$. Except for the bare GC electrode which showed no activity all the Pd deposits behaved in a broadly similar way compared to their performance for ORR in $\mathrm{KOH}$. The $10 \%$ mixture produced slightly more active deposits with a specific activity reaching $0.6 \mathrm{~A} \mathrm{~cm}^{-2} \mathrm{mg}^{-1}$ at circa $+0.34 \mathrm{~V}$; at this potential the current densities scaled as follows with respect to the $10 \%$ mixture: $j_{10 \%}=1.2 \times j_{2 \%}=1.7 \times j_{48 \%}=2.2 \times j_{0 \%}$.

\section{Analysis}

Table 3 summarises the specific activities recorded with the different Pd deposits for the test reactions considered.

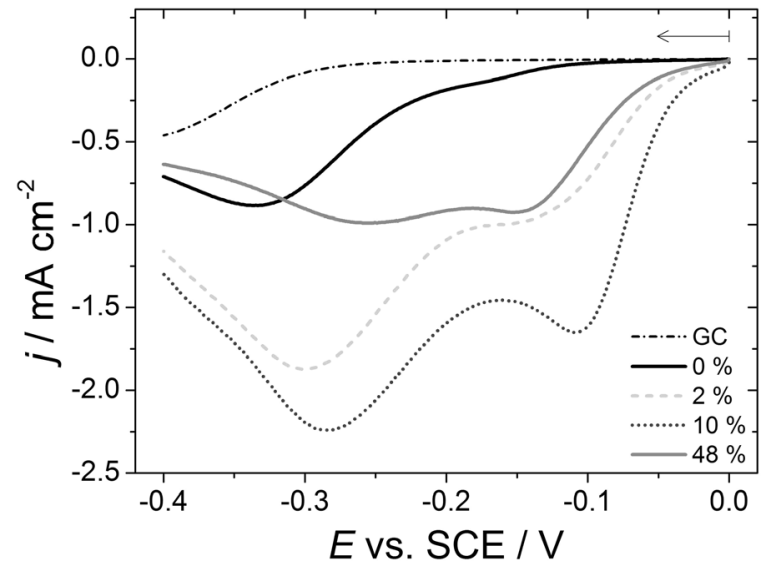

Fig. 9 Linear sweep voltammograms for the reduction of oxygen recorded in $\mathrm{O}_{2}$ saturated $0.5 \mathrm{M} \mathrm{KOH}$ at $100 \mathrm{mV} \mathrm{s}^{-1}$ with $\mathrm{GC}$ electrodes decorated with the Pd deposits. The legend indicates the corresponding plating mixtures. 
Table 3 Specific activities recorded with the Pd modified GC electrodes for the formic acid oxidation reaction (FAOR), ethanol oxidation reaction (EOR), hydrogen evolution reaction (HER), oxygen evolution reaction (OER) and oxygen reduction reaction (ORR)

\begin{tabular}{lcrlrl}
\hline & \multicolumn{5}{l}{ Specific activities/A cm } \\
\cline { 2 - 6 } $\mathrm{C}_{16} \mathrm{EO}_{8} \mathrm{wt} \%$ & $\mathrm{FAOR}^{a}$ & $\mathrm{EOR}^{b}$ & $\mathrm{HER}^{c}$ & $\mathrm{OER}^{d}$ & $\mathrm{ORR}^{e}$ \\
\hline 0 & 1.3 & 2.5 & 0.04 & 2.1 & 0.02 \\
2 & 5.2 & 6.4 & 0.3 & 24.0 & 0.3 \\
10 & 13.3 & 23.4 & 1.0 & 52.4 & 0.7 \\
48 & 8.2 & 7.6 & 0.2 & 17.8 & 0.3
\end{tabular}

${ }^{a}$ From Fig. 5 at the forward peak. ${ }^{b}$ From Fig. 6 at the forward peak. ${ }^{c}$ From Fig. 7 at -0.099 V. ${ }^{d}$ From Fig. 8 at +1.198 V. ${ }^{e}$ From Fig. 9 at $-0.109 \mathrm{~V}$.

In this table, each experiment was undertaken with the same amount of Pd deposited. Since the criterion chosen to assess activity was different for each reaction, respectively, the peak current for the formic acid and ethanol oxidations and the current at a fixed potential for the $\mathrm{H}$ and $\mathrm{O}_{2}$ evolution and $\mathrm{O}_{2}$ reduction reactions, Table 3 is not designed to compare the performance of a given deposit across all reactions but rather to compare the performance of the different deposits for a given reaction. Overall the $10 \%$ mixture produces the most active deposits followed by the 2 and $48 \%$ mixtures which share similar activities; nonetheless the deposits formed without the surfactant are reasonably active. These results are consistent with the morphology observed with the FEG-SEM images, Fig. 3 and with the voltammetry recorded in acid, Fig. 4. The Pd nanoparticles which form the building blocks of the clusters and agglomerates observed appear clearer in the SEM for the $10 \%$ mixture than with the other mixtures. They are not more dispersed as distances between the nanoparticles are similar for all deposits, even in the absence of the surfactant; rather the flaky 2D texture of the deposits formed with the $10 \%$ mixture is thought to give more exposure of the particles to the solution and this is reflected in their enhanced electrochemical activity.

Although no attempt was made to conduct an exhaustive comparison of the activities obtained with those previously reported, they generally compare well. ${ }^{21-25}$ In all cases the deposits prepared using the surfactant template perform overwhelmingly better than those prepared without the template. Normalising the electroactive areas and specific activities to the corresponding quantities obtained in the absence of the surfactant reveals a striking and unexpected outcome as presented in Table 4.

Table 4 shows that the use of the surfactant template produces large enhancements in electrochemical activity which are far in excess of those expected on the basis of the increased electroactive areas. For example the electroactive area of the deposits prepared with the $10 \%$ mixture is 2.7 times larger than that prepared with the $0 \%$ mixture but its activity for the formic acid oxidation is ten times larger. The template produces modest increases in electroactive areas, irrespective of the surfactant weight ratio, but the electrochemical activities obtained are significantly larger, especially for the $10 \%$ mixture.
Table 4 Normalised electroactive areas and normalised specific activities for the $2 \%, 10 \%$ and $48 \%$ mixtures taking the $0 \%$ mixture as the reference

\begin{tabular}{|c|c|c|c|c|c|c|}
\hline \multirow{2}{*}{$\begin{array}{l}\mathrm{C}_{16} \mathrm{EO}_{8} \\
\text { wt } \%\end{array}$} & \multirow{2}{*}{$\begin{array}{l}\text { Normalised electroactive } \\
\text { area }\end{array}$} & \multicolumn{5}{|c|}{ Normalised specific activities } \\
\hline & & $\mathrm{FAOR}^{a}$ & ${ }^{a} \mathrm{EOR}^{b}$ & ${ }^{b} \mathrm{HER}^{c}$ & ${ }^{c} \mathrm{OER}^{d}$ & $\mathrm{ORR}^{e}$ \\
\hline 2 & 2.2 & 4 & 3 & 7 & 11 & 19 \\
\hline 10 & 2.7 & 10 & 9 & 26 & 25 & 39 \\
\hline 48 & 1.4 & 6 & 3 & 6 & 8 & 15 \\
\hline
\end{tabular}

${ }^{a}$ From Fig. 5 at the forward peak. ${ }^{b}$ From Fig. 6 at the forward peak. ${ }^{c}$ From Fig. 7 at -0.099 V. ${ }^{d}$ From Fig. 8 at +1.198 V. ${ }^{e}$ From Fig. 9 at $-0.109 \mathrm{~V}$.

\section{Conclusion}

These results clearly demonstrate that the lyotropic liquid crystal template influences the morphology and electrochemical activity of the Pd deposits prepared on the GC substrates. The differences in morphology are reflected in the voltammetry recorded in acid but the electroactivity of the deposits for all the test reactions considered far exceeds what might be reasonably expected on the basis of the electroactive areas. It was beyond the scope of the study to investigate the structure of the nanoparticles but a possible explanation is that the presence of the template and the use of large overpotentials produced facetted particles with far more atoms on edges than those produced without a surfactant. We have no explanation to support the superior performance of the deposits prepared with the $10 \%$ mixture and are now planning to investigate the structure-activity relationship over a range of surfactant weight ratios in the micellar phase.

\section{Acknowledgements}

N.A. acknowledges the financial support from the Ministry of Higher Education, Saudi Arabia. G.D. acknowledges the award of a fellowship by the Hanse Wissenschaftskolleg, Institute for Advanced Study, Delmenhorst, Germany.

\section{Notes and references}

1 R. Rioux, H. Song, M. Grass, S. Habas, K. Niesz, J. Hoefelmeyer, P. Yang and G. Somorjai, Top. Catal., 2006, 39, 167-174.

2 S. Hrapovic, Y. Liu, K. B. Male and J. H. Luong, Anal. Chem., 2004, 76, 1083-1088.

3 M. Yang, Y. Yang, Y. Liu, G. Shen and R. Yu, Biosens. Bioelectron., 2006, 21, 1125-1131.

4 R. Narayanan and M. A. El-Sayed, J. Am. Chem. Soc., 2004, 126, 7194-7195.

5 G. S. Attard, C. G. Goltner, J. M. Corker, S. Henke and R. H. Templer, Angew. Chem., Int. Ed. Engl., 1997, 36, 1315-1317.

6 G. S. Attard, P. N. Bartlett, N. R. B. Coleman, J. M. Elliott, J. R. Owen and J. H. Wang, Science, 1997, 278, 838-840.

7 G. S. Attard, P. N. Bartlett, N. R. B. Coleman, J. M. Elliott and J. R. Owen, Langmuir, 1998, 14, 7340-7342.

8 S. Guerin and G. S. Attard, Electrochem. Commun., 2001, 3, 544-548. 
9 P. N. Bartlett, B. Gollas, S. Guerin and J. Marwan, Phys. Chem. Chem. Phys., 2002, 4, 3835-3842.

10 P. N. Bartlett and S. Guerin, Anal. Chem., 2003, 75, 126-132.

11 G. Denuault, C. Milhano and D. Pletcher, Phys. Chem. Chem. Phys., 2005, 7, 3545-3551.

12 T. Imokawa, K.-J. Williams and G. Denuault, Anal. Chem., 2006, 78, 265-271.

13 N. A. Al Abass and G. Denuault, in preparation.

14 L. D. Burke and J. K. Casey, J. Electrochem. Soc., 1993, 140, 1284-1291.

15 D. A. J. Rand and R. Woods, J. Electroanal. Chem., 1971, 31, 29-38.

16 D. A. J. Rand and R. Woods, J. Electroanal. Chem., 1972, 35, 209-218.

17 O. Winjobi, Z. Zhang, C. Liang and W. Li, Electrochim. Acta, 2010, 55, 4217-4221.
18 X. Wang, Y. Tang, Y. Gao and T. Lu, J. Power Sources, 2008, 175, 784-788.

19 Y. W. Lee, M. Kim, Y. Kim, S. W. Kang, J.-H. Lee and S. W. Han, J. Phys. Chem. C, 2010, 114, 7689-7693.

20 Z. Liang, T. Zhao, J. Xu and L. Zhu, Electrochim. Acta, 2009, 54, 2203-2208.

21 Y.-H. Qin, H.-C. Li, H.-H. Yang, X.-S. Zhang, X.-G. Zhou, L. Niu and W.-K. Yuan, J. Power Sources, 2011, 196, 159-163.

22 L. D. Zhu, T. S. Zhao, J. B. Xu and Z. X. Liang, J. Power Sources, 2009, 187, 80-84.

23 H. Meng, S. Sun, J.-P. Masse and J.-P. Dodelet, Chem. Mater., 2008, 20, 6998-7002.

24 C. Du, M. Chen, W. Wang, G. Yin and P. Shi, Electrochem. Commun., 2010, 12, 843-846.

25 V. Selvaraj, M. Alagar and I. Hamerton, Appl. Catal., B, 2007, 73, 172-179. 